\title{
KNOWLEDGE OF STROKE RISK FACTORS AMONGST BLACK DIABETIC, HyPERTENSIVE AND STROKE PATIENTS
}

\begin{abstract}
The objective of this study was to assess and compare the knowledge of black patients diagnosed with hypertension, diabetes and stroke about the risk factors for stroke. Four groups made up of 33 subjects (hypertensive, diabetic, stroke and control group) were interviewed using open-ended questions and a structured questionnaire. Qualitative coding, frequencies and proportions were used to determine their knowledge. Groups were compared with respect to percentage knowledge using the chi-square

BOGOSHI G, MSc (Physiotherapy)1, STEWART A, PhD ${ }^{1}$, HALE L, PhD², FRITZ V, PhD ${ }^{1}$

${ }^{1}$ University of the Witwatersrand.
2 University of 0 tago. statistic at a 0.05 level of significance. Stress was mentioned as the most important risk factor in all groups. Although identification of stroke risk factors was inadequate, the diabetic group was found to be significantly better in identifying some of the risk factors (salt $-p=0,05$; sugar - $p=0,001$; fat $-p=0,004$; moderate smoking $-p=0,05$; weight $-p=0,002$ ).
\end{abstract}

KEY WORDS: STROKE, KNOWLEDGE, RISK FACTORS, DIABETIC, HYPERTENSIVE.

\section{INTRODUCTION}

Stroke is an important public health problem in South Africa. About 8\% of all deaths reported in South Africa are caused by stroke (Steyn et al 1992). This is attributed to inadequate blood pressure control (Steyn, 1998). Many of these deaths occur before the age of 65 and consequently may have a major impact on the South African economy (Steyn, 1998).

In 1998, Hale et al found that only $20 \%$ of a stroke group whom they interviewed understood that hypertension could have caused their stroke. Samsa et al (1997) found that only $42 \%$ of patients with a previous history of stroke were aware of their increased risk for a subsequent stroke.

Chronic diseases such as hypertension and diabetes require patient education to effectively manage the disease and prevent adverse health outcomes (Williams et al, 1998). Stroke, one of the complications of these conditions, can lead to residual disability and handicap which can be devastating to both patient and family. Therefore stroke prevention is essential and patients need to know the risk factors that can lead to a stroke. Thus patient education plays a crucial role in facilitating patients' acceptance of their diagnosis and understanding of the health behaviour changes required (Grueninger, 1995). Traditionally patient education relies heavily on written material for information on disease management and self care instruction. Despite the availability of extensive health education materials with relatively consistent content, much is written at too high a level for patients with low literacy levels to comprehend (Williams, et al 1998).

Knowledge about stroke influences the time of presentation to hospital (Williams et al 1997). Samsa et al (1997) concluded that patients who recognise their increased risk for stroke are more likely to engage in, and adhere to, stroke prevention practices than those who do not. Therefore prevention of stroke will probably rely heavily on the knowledge that patients have about the risk factors of stroke.

The aim of this study was to assess and compare the knowledge of the risk factors for stroke, of patients diagnosed with hypertension, diabetes or stroke and a control group.

\section{SUBJ ECTS AND PROCEDURE}

Prior to the commencement of this study, ethical clearance from the Committee for research on human subjects of the University of the Witwatersrand was obtained (Clearance number: M990402).

For the purposes of this study a sample of convenience was taken from a black population of diabetic, hypertensive and stroke patients attending clinics at the Johannesburg hospital. The control group, was a sample drawn from a black population of patients admitted into the neurology ward of the same hospital and from patients attending physiotherapy out-patients who had diseases unrelated to the three mentioned above. All groups were informed about the study and signed consent prior to participation in the study.

The experimental groups were sampled as follows;

\section{CORRESPONDENCE TO:}

Ms G Bogoshi

Honorary Lecturer,

Physiotherapy Department,

University of the Witwatersrand Chris Hani Baragwanath Hospital, Administration Building, Room 815

P.O. BERTSHAM

Johannesburg, South Africa

Tel: $\quad$ (011) 933-9154

E-mail: gmbogoshi@webmail.co.za 
Patients who attended the relevant clinics at Johannesburg hospital were recruited if they fulfilled the following criteria:

- Black male and female patients above 25 years of age

- Had been diagnosed with either diabetes, hypertension or stroke, at least one year previously at their respective clinics

- Had been attending the relevant clinic at Johannesburg hospital for at least one year

Patients were included in the study from July 1999 to August 2000.

Subjects who had unintelligible speech and/or cognitive problems that hampered comprehension were not included in the study.

\section{DEVELOPMENT AND \\ ADMINISTRATION OF QUESTIONNAIRE}

The first author developed a questionnaire. A physiotherapy assistant was trained to administer the questionnaire. She was chosen to conduct the interview because of her ability to speak and understand five different South African languages. The validity and the intrarater reliability of the questionnaire were established prior to the commencement of the study in the following manner:

The validity of the questionnaire was established by discussing the questionnaire with a group of physiotherapists experienced in the field and with a group of similar patients. The intra-rater reliability of the questionnaire was established by having the physiotherapy assistant interview five patients on two different occasions and comparing the answers.

The questionnaire was divided into two sections. The first quantitative part established the demographic and medical background while the second part established the knowledge of stroke risk factors. Patients were given statements to which they had to answer in a true/false format.

A descriptive qualitative approach was also used. This consisted of structured interviews with four open-ended questions that were conducted with patients prior to the administration of the questionnaire. Patients were interviewed on a one to one basis.

\section{QUANTITATIVE DATA ANALYSIS}

Data were summarized using frequencies and proportions (percentages). Groups were compared with respect to percentage knowledge using the chi-square test. A p-value less than 0,05 was considered significant.

\section{QUALITATIVE ANALYSIS}

Categories of coding were chosen according to the most important information on causes of stroke that patients needed to have (Shepard, 1993).

'What is a stroke?' was described and coded under four headings, namely:

- Causes of stroke

- Results of stroke

- Stress and social issues

- Other - answers that were totally unrelated to any of the above.

'What do you think are the risk factors of stroke?' The answers were coded as those who knew the risk factors and those who did not know.

'Do you think you are at risk of stroke?' was coded as those who said 'yes' and those who said 'no'.

'Has the doctor or nurse told you that you are at risk of a stroke', was coded as yes or no.

\section{RESULTS}

Four groups of 33 subjects were interviewed. The demographic data of the patients in the four groups is illustrated in Table 1.

\section{MEDICAL INFORMATION}

The medical information of the diabetic, hypertension and stroke groups is presented in Table 2.

\section{RESULTS OF OPEN- ENDED QUESTIONS}

The responses to the open-ended questions were summarised as follows:

\section{a) What is a stroke?}

The majority of subjects in all groups described a stroke by explaining the results of the stroke. The most common answer was 'one side of the body not working'.

\section{b) What are the risk factors for stroke?}

The majority of subjects in all groups mentioned at least one risk factor with high blood pressure being the most common. A few subjects in the diabetic group mentioned diabetes. Other risk factors mentioned in the diabetic group were poor diet, smoking and alcohol. In all groups stress related incidences were mentioned quite frequently. Less than seven subjects in all groups did not know any of the risk factors.

\section{c) Do you think you are at risk of stroke and why?}

About half the patients from all groups thought that they were at risk. Those who thought that they were not at risk, mentioned that they were either taking their medication regularly or that they were not under any stress.

\section{d) Has the doctor/ nurse told you that you are at risk of stroke?}

The majority of subjects in all groups said that they had not been told that they were at risk of a stroke.

High blood pressure, stress and "thinking too much" were most frequently mentioned in all groups as risk factors. Heavy smoking and "working hard' were highly appreciated by all groups as risk factors for stroke. (Table $3 \& 4$ )

\section{DISCUSSION}

In this study, subjects were first asked to explain what they thought a stroke was. In all groups the common answer was related to the changes that could be seen visually. They mentioned "one side of the body not working" as their definition of stroke. This means that they could probably recognise the signs and symptoms of stroke. In all groups few subjects explained stroke by mentioning the causes of stroke. The most likely risk factor mentioned was high blood pressure. Twenty four percent of patients in the diabetic group compared to the hypertensive and stroke group (12\% and $6 \%$ respectively) mentioned high blood pressure. Although $64 \%$ of patients in the stroke group were diagnosed with high blood pressure, only $6 \%$ explained stroke as caused by increased blood pressure. Hale et al (1998) found that $20 \%$ of their stroke group understood that hypertension had probably caused their stroke. The subjects were unaware that hypertension and stroke were causally linked. Their findings are similar 
to the results of this study. None of the control group mentioned any risk factors when explaining stroke.

The patients' ability to report stroke risk factors spontaneously (open ended questions) was rated poorly in all groups. The open-ended questions were asked first to avoid having other parts of the questionnaire influence patients' responses. Stress, not a commonly accepted stroke risk factor, was the attribute most commonly thought by all groups to be a risk factor for stroke. These findings are similar to Kattapong et al (1998). Individuals diagnosed as diabetics are more likely to report diabetes as a risk factor than those without a diagnosis of diabetes. In a similar population group Kattapong et al (1990), established that individuals with selfreported diagnoses of diabetes were significantly more likely to mention diabetes as a risk factor than those without. The diabetic group was also the only group that reported diabetes as a risk factor. Twenty one percent of patients in the diabetic and stroke group mentioned

Table 1: Distribution of demographic characteristics for groups.

\begin{tabular}{|c|c|c|c|c|c|c|c|c|c|c|}
\hline & \multicolumn{2}{|c|}{$\begin{array}{c}\text { DIABETIC } \\
n=33\end{array}$} & \multicolumn{2}{|c|}{$\begin{array}{l}\text { HYPERTEN SIVE } \\
n=33\end{array}$} & \multicolumn{2}{|c|}{$\begin{array}{c}\text { STROKE } \\
n=33\end{array}$} & \multicolumn{2}{|c|}{$\underset{n=33}{\operatorname{CONTROL}}$} & \multicolumn{2}{|c|}{ TOTAL } \\
\hline & No Subj. & $\%$ & No Subj. & $\%$ & No Subj. & $\%$ & No Subj. & $\%$ & No Subj. & $\%$ \\
\hline \multicolumn{11}{|l|}{ Age } \\
\hline$<40$ years & 4 & 12.1 & 3 & 9.1 & 8 & 24.2 & 17 & 51.5 & 32 & 24.2 \\
\hline $40-49$ years & 8 & 24.2 & 9 & 27.3 & 11 & 33.3 & 8 & 24.2 & 36 & 27.3 \\
\hline $50-59$ years & 17 & 51.1 & 17 & 51.5 & 12 & 36.4 & 5 & 15.2 & 51 & 38.6 \\
\hline $60-70$ years & 4 & 12.1 & 4 & 12.1 & 1 & 3.0 & 2 & 6.1 & 11 & 8.3 \\
\hline$>70$ years & 0 & 0 & 0 & 0 & 1 & 3.0 & 1 & 3.0 & 2 & 1.5 \\
\hline \multicolumn{11}{|l|}{ Gender } \\
\hline Female & 13 & 39.4 & 11 & 33.3 & 13 & 39.4 & 18 & 54.5 & 55 & 41.7 \\
\hline Male & 20 & 60.6 & 22 & 66.7 & 20 & 60.6 & 15 & 32.7 & 77 & 58.3 \\
\hline \multicolumn{11}{|l|}{ Ethnic group } \\
\hline Northern Sotho & 8 & 24.2 & 5 & 15.2 & 3 & 9.1 & 8 & 24.2 & 24 & 18.2 \\
\hline Sotho & 3 & 9.1 & 1 & 3.0 & 6 & 18.2 & 2 & 6.1 & 12 & 9.1 \\
\hline Zulu & 18 & 54.5 & 15 & 45.5 & 9 & 27.3 & 12 & 36.4 & 54 & 40.9 \\
\hline Xhosa & 3 & 9.1 & 5 & 15.2 & 3 & 9.1 & 4 & 12.1 & 15 & 11.4 \\
\hline Venda & 0 & 0 & 0 & 0 & 1 & 3.0 & 1 & 3.0 & 2 & 1.5 \\
\hline Shangaan & 0 & 0 & 1 & 3.0 & 0 & 0 & 1 & 3.0 & 2 & 1.5 \\
\hline 0 ther & 1 & 3.1 & 6 & 18.2 & 11 & 33.3 & 5 & 13.2 & 23 & 17.4 \\
\hline \multicolumn{11}{|l|}{ Education } \\
\hline No formal education & 5 & 15.2 & 4 & 12.1 & 1 & 3.0 & 1 & 3.0 & 11 & 8.3 \\
\hline Primary: Grade 1 - 6 & 13 & 39.4 & 14 & 42.4 & 13 & 39.4 & 17 & 51.5 & 57 & 43.2 \\
\hline Secondary: grade 7 - 10 & 11 & 33.3 & 14 & 42.4 & 16 & 48.5 & 10 & 30.3 & 51 & 38.6 \\
\hline Matric & 0 & 0 & 0 & 0 & 3 & 9.1 & 4 & 12.1 & 7 & 5.3 \\
\hline Tertiary & 4 & 12.1 & 1 & 3.0 & 0 & 0 & 1 & 3.0 & 6 & 4.5 \\
\hline \multicolumn{11}{|l|}{ Employment Status } \\
\hline Yes & 22 & 66.7 & 24 & 72.7 & 16 & 48.5 & 15 & 45.5 & 77 & 58.3 \\
\hline No & 11 & 33.3 & 9 & 27.3 & 17 & 51.2 & 18 & 54.5 & 55 & 41.7 \\
\hline \multicolumn{11}{|l|}{ Income per month rands } \\
\hline$<\mathrm{R} 500,00$ & 13 & 39.4 & 13 & 39.4 & 19 & 57.6 & 22 & 66.7 & 67 & 50.8 \\
\hline$R \quad 501,00-R 1500,00$ & 17 & 51.5 & 18 & 54.5 & 13 & 39.4 & 7 & 21.2 & 55 & 41.7 \\
\hline R1 $500,00-R 2500,00$ & 3 & 9.1 & 1 & 3.0 & 1 & 3.0 & 3 & 9.1 & 8 & 6.1 \\
\hline R2 $500,00-$ R3 500,00 & 0 & 0 & 1 & 3.0 & 0 & 0 & 1 & 3.0 & 2 & 1.5 \\
\hline
\end{tabular}


high blood pressure as a risk factor compared to $18 \%$ in the hypertensive and $9 \%$ in the control group. Although very few patients in the control group could correctly identify risk factors, they mentioned a greater variety of risk factors as compared to the other three groups. These included obesity, lack of exercise and one even mentioned HIV.

The stroke group indicated that they were at risk for stroke more than the other groups with $61 \%$ (highest amongst all groups) indicating that a doctor or nurse had told them that they are at risk for a second stroke. The majority of subjects in all groups who felt that they were not at risk said they were taking their medication or were not stressed. This indicates the poor level of understanding of their risk of stroke. It could be argued that the doctor could probably have informed them of their risk, however because the subject was probably discussed in a language that they did not understand very well, their comprehension was compromised. Visual materials and other forms of communication like radio and television represent an important form of communication in different languages and could probably be used efficiently to highlight information and advice.

The patients' ability to correctly identify stroke risk factors was greater than their ability to spontaneously report risk factors. The diabetic group identified a greater number of risk factors than other groups (see Table 3). The stroke group was significantly more likely to identify blood pressure and previous stroke than the other group $(\mathrm{p}<0.05$ and 0.001 respectively). For factors such as diet,

Table 2: Medical Information of all groups.

\begin{tabular}{|c|c|c|c|c|c|c|c|c|}
\hline & \multicolumn{2}{|c|}{$\begin{array}{c}\text { DIABETIC } \\
n=33\end{array}$} & \multicolumn{2}{|c|}{$\begin{array}{l}\text { HYPERTEN SION } \\
n=33\end{array}$} & \multicolumn{2}{|c|}{$\begin{array}{c}\text { STRO KE } \\
n=33\end{array}$} & \multicolumn{2}{|c|}{ TOTAL } \\
\hline & No Subj. & $\%$ & No Subj. & $\%$ & No Subj. & $\%$ & No Subj. & $\%$ \\
\hline \multicolumn{9}{|c|}{ First diagnosed with diabetes } \\
\hline N ever & 1 & 3.0 & 31 & 93.9 & 25 & 75.8 & 62 & 62.6 \\
\hline 1 year & 10 & 30.3 & 1 & 3.0 & 4 & 12.1 & 19 & 19.2 \\
\hline 1 - 5 years & 13 & 39.4 & 1 & 3.0 & 4 & 12.1 & 13 & 13.1 \\
\hline$>5$ years & 9 & 27.3 & 0 & 0.0 & 0 & 0.0 & 5 & 5.1 \\
\hline N ever & 11 & 33.3 & 0 & 0.0 & 12 & 36.4 & 22 & 22.2 \\
\hline \multicolumn{9}{|c|}{ First diagnosed with hypertension } \\
\hline 1 year & 9 & 27.3 & 5 & 15.2 & 15 & 15.2 & 20 & 20.2 \\
\hline 1 - 5 years & 9 & 27.3 & 16 & 48.5 & 6 & 18.2 & 31 & 31.3 \\
\hline$>5$ years & 4 & 12.1 & 12 & 36.4 & 10 & 30.3 & 26 & 26.3 \\
\hline N ever & 31 & 93.9 & 31 & 93.9 & 2 & 6.1 & 63 & 63.6 \\
\hline \multicolumn{9}{|c|}{ First diagnosed with Stroke } \\
\hline 1 year & 1 & 3.0 & 0 & 0.0 & 16 & 48.5 & 17 & 17.2 \\
\hline 1 - 5 years & 0 & 0 & 2 & 6.1 & 10 & 30.3 & 13 & 13.1 \\
\hline$>5$ years & 1 & 3.0 & 0 & 0.0 & 5 & 15.2 & 6 & 6.1 \\
\hline \multicolumn{9}{|c|}{ Length of attendance at clinic } \\
\hline 1 year & 12 & 36.4 & 8 & 24.2 & 19 & 57.6 & 36 & 36.4 \\
\hline 1 - 5 years & 14 & 42.4 & 16 & 48.5 & 8 & 24.2 & 36 & 36.4 \\
\hline$>5$ years & 7 & 21.2 & 9 & 27.3 & 6 & 18.2 & 27 & 27.3 \\
\hline \multicolumn{9}{|c|}{ Knowledge of risk factors aquired from: } \\
\hline Doctor & 7 & 21.2 & 6 & 18.2 & 16 & 48.5 & 29 & 22.0 \\
\hline N urse & 6 & 18.2 & 8 & 24.2 & 7 & 21.2 & 21 & 15.9 \\
\hline TV/ Radio & 2 & 6.1 & 8 & 24.2 & 2 & 6.1 & 12 & 9.1 \\
\hline Poster/ Pamphlets & 2 & 6.1 & 2 & 6.1 & 6 & 18.2 & 10 & 7.6 \\
\hline Word of mouth & 3 & 9.1 & 0 & 0.0 & 0 & 0.0 & 3 & 2.3 \\
\hline Family member & 1 & 3.0 & 0 & 0.0 & 4 & 12.1 & 5 & 3.8 \\
\hline
\end{tabular}


smoking, salt intake, diabetic patients demonstrated a better knowledge as compared to other groups. The diabetic group is usually exposed to the services of a dietician and they are more likely to report diet related risk factors than the other groups. The control group was least likely to identify risk factors. Stress

Table 3: Patients' knowledge of risk factors presented as percentages (True/ false questions).

\begin{tabular}{|l|c|c|c|c|c|}
\hline & DM & HT & Stroke & Control & p value \\
\hline Diet & 61 & 46 & 33 & 42 & 0.16 \\
\hline High blood pressure & 94 & 91 & 94 & 85 & 0.5 \\
\hline Low blood pressure & 36 & 30 & 27 & 18 & 0.42 \\
\hline Uncontrolled blood pressure & 88 & 64 & 67 & 64 & 0.09 \\
\hline Smoking & 73 & 61 & 61 & 58 & 0.59 \\
\hline Heavy smoking & 76 & 73 & 76 & 73 & 0.98 \\
\hline O ccasional smoking & 51 & 42 & 36 & 33 & 0.55 \\
\hline No exercise & 82 & 82 & 67 & 64 & 0.19 \\
\hline Stress & 91 & 88 & 85 & 73 & 0.2 \\
\hline W orking hard & 70 & 64 & 67 & 70 & 0.94 \\
\hline Thinking too much & 94 & 97 & 91 & 88 & 0.54 \\
\hline No rest & 94 & 82 & 85 & 82 & 0.45 \\
\hline Alcohol & 79 & 67 & 76 & 67 & 0.59 \\
\hline Diabetes & 79 & 51 & 64 & 77 & 0.12 \\
\hline Salt & 84 & 42 & 45 & 51 & 0.06 \\
\hline Sugar & 88 & 79 & 67 & 61 & 0.001 \\
\hline Fat & 94 & 88 & 76 & 61 & 0.004 \\
\hline Moderate smoking & 64 & 42 & 45 & 30 & 0.06 \\
\hline W eight & 97 & 88 & 73 & 64 & 0.002 \\
\hline Blood pressure & 30 & 12 & 88 & 26 & 0.001 \\
\hline Previous stroke & 88 & 91 & 67 & 0.05 \\
\hline
\end{tabular}

$\mathrm{DM}=$ Diabetes mellitus

$\mathrm{HT}=\mathrm{Hypertension}$

and related factors were identified more frequently as risk factors for stroke than conventional risk factors.

The patients' ability to identify stroke risk factors from a list (true/false questions), and to rank order three risk factor, was better than their ability to spontaneously report stroke risk factors (Table $3 \& 4$ ). Stress was still named as the most important risk factor. None of the subjects mentioned previous stroke as a risk factor (Table 4). Less than $25 \%$ in all groups mentioned hypertension as the second most important risk factor for stroke. Even though they were given the eight risk factors namely stress, hypertension, smoking, alcohol, diet, diabetes, increased weight, previous stroke to choose from, a few subjects in all groups felt that not taking their medication was the most important risk factor.

The results of this study are of value in that they identify the lack of knowledge about stroke risk factors amongst black diabetic, hypertensive and stroke patients who had attended a tertiary care hospital clinic for more than a year. The results also demonstrate the need to evaluate the teaching methods used at clinics to impart this information to patients.

Williams et al (1998) reported that chronic diseases such as hypertension and diabetes required patient education to achieve adequate control and prevent adverse health outcomes.Grueniger (1995) also reported that education plays a very important role in helping

Table 4: Ranking of the most important risk factors in the diabetic, hypertensive, stroke and control group.

\begin{tabular}{|c|c|c|c|c|c|c|c|c|c|c|c|c|}
\hline & \multicolumn{3}{|c|}{ DIABETIC $n=33$} & \multicolumn{3}{|c|}{ HYPERTENSIO N n=33 } & \multicolumn{3}{|c|}{ STROKE $n=33$} & \multicolumn{3}{|c|}{ CONTRO L $n=33$} \\
\hline & $\begin{array}{c}1^{*} \\
\text { No. of } \\
\text { Response }\end{array}$ & $\begin{array}{c}2^{*} \\
\text { No. of } \\
\text { Response }\end{array}$ & $\begin{array}{c}3^{*} \\
\text { No. of } \\
\text { Response }\end{array}$ & $\begin{array}{c}1^{*} \\
\text { No. of } \\
\text { Response }\end{array}$ & $\begin{array}{c}2^{*} \\
\text { No. of } \\
\text { Response }\end{array}$ & $\begin{array}{c}3^{*} \\
\text { No. of } \\
\text { Response }\end{array}$ & $\begin{array}{c}1^{*} \\
\text { No. of } \\
\text { Response }\end{array}$ & $\begin{array}{c}2^{*} \\
\text { No. of } \\
\text { Response }\end{array}$ & $\begin{array}{c}3^{*} \\
\text { No. of } \\
\text { Response }\end{array}$ & $\begin{array}{c}1^{*} \\
\text { No. of } \\
\text { Response }\end{array}$ & $\begin{array}{c}2^{*} \\
\text { No. of } \\
\text { Response }\end{array}$ & $\begin{array}{c}3^{*} \\
\text { No. of } \\
\text { Response }\end{array}$ \\
\hline Stress & 9 & 10 & 9 & 12 & 6 & 11 & 12 & 7 & 7 & 13 & 13 & 9 \\
\hline Hypertension & 5 & 5 & 2 & 6 & 0 & 1 & 7 & 7 & 0 & 8 & 2 & 2 \\
\hline Smoking & 0 & 3 & 2 & 2 & 0 & 7 & 1 & 2 & 7 & 2 & 5 & 3 \\
\hline Alcohol & 6 & 2 & 1 & 3 & 7 & 1 & 4 & 4 & 2 & 6 & 6 & 2 \\
\hline Diet & 4 & 5 & 9 & 5 & 9 & 7 & 4 & 5 & 6 & 0 & 1 & 4 \\
\hline DM & 4 & 6 & 4 & 0 & 0 & 0 & 0 & 0 & 2 & 1 & 2 & 1 \\
\hline W eight/ 0 besity & 3 & 0 & 1 & 2 & 4 & 1 & 3 & 1 & 4 & 0 & 2 & 3 \\
\hline Previous Stroke & 0 & 0 & 0 & 0 & 0 & 0 & 0 & 0 & 0 & 0 & 0 & 0 \\
\hline
\end{tabular}

1* - most important $\quad 2 *$ - second most important $3 *$ - third most important

$\mathrm{N}$ o - N umber of responses 
patients to accept their diagnosis and understand the required health behaviour changes. In this study, it was found that the majority of subjects in all groups had received primary school education with less than $13 \%$ having matriculated or having tertiary education and up to $15 \%$ not having any formal education. This, as well as the fact that any patient education in the clinics is mostly conducted in English by doctors, posters and pamphlet information written in English means that the majority of the patients probably do not understand the vital information needed about their diseases. The majority of patients (diabetic, 79\%; hypertensive, 64\%; stroke, $61 \%$ ) in this study indicated that neither the nurse nor the doctor had told them that they were at risk of stroke. When asked about where they acquired their knowledge of risk factors, very few mentioned posters or pamphlets (diabetic, $6 \%$; hypertensive, 6\%; stroke, 18\%). There are a number of good posters in the clinics explaining the risk factors for stroke and pamphlets are also issued to the patients on a regular basis, but the fact that they are also written in English means that patients have difficulty comprehending what is written. The nurses working in the clinics speak all the languages with which most patients are familiar. They can thus play a very important educational role in this regard.

\section{CONCLUSION AND RECOMMENDATIONS}

This study was undertaken to establish and compare stroke risk factor knowl- edge amongst black diabetic, hypertensive and stroke patients. The following conclusions can be drawn from the study:

- Knowledge of stroke risk factors amongst all groups was inadequate.

- The diabetic group was significantly better in identifying some risk factors as compared to other groups, even though their overall knowledge was also inadequate.

- As this study was done at one tertary care hospital only, further studies should be undertaken at other types of health care facilities.

It is recommended as a result of this study that physiotherapists could and should play a role in the appropriate education of patients about the nature of their disease and the risk factors involved.

\section{REFERENCES}

Grueninger U J 1995 Arterial hypertension: Lessons from patient education. Patient Education Counsel 26: 37 - 55

Hale L A, Fritz V U, Eales C J 1998 Do stroke patients realise that a consequence of hypertension is stroke? South African Medical Journal 18(4): 451 - 454

Kattapong V J, Longstreth W T, Kukull W A, Howard D B, Bowes J I, Wilson B E, Bigney J B, Becker T M 1998 Stroke risk factor knowledge in Hispanic and non-Hispanic white women in new Mexico: Implications for targeted prevention strategies. Health Care Women International 19(4): 313 - 325

Samsa G P, Cohen S J, Goldstein L B, Bonito A J, Duncan P W, Enarson C, DeFriese G H, Horner R D, Matchar D B 1997 Knowledge of risk among patients at increased risk for stroke. Stroke 28: 916 - 921

Shepard K F 1993 Chapter 8: Questionnaire design use. In: Research in physiotherapy therapy. Bork C E (editor), first edition. Philadelphia, J B Lippincott Company

Steyn K, Fourie J, Bradshaw D 1992 The impact of chronic diseases of lifestyle and their major risk factors on mortality in South Africa. South African Medical Journal 82: $227-231$

Steyn K 1998 Epidemiology of hypertension in South Africa: New data. Continuing Medical Education 16(10): 917 - 922

Williams L S, Bruno A, Rouch D, Marriott D J 1997 Stroke patients knowledge of stroke: Influence on time to presentation. Stroke 28: $912-915$

Williams M V, Baker D W, Parker R M, Nurss J R 1998 Relationship of functional health literacy to patients' knowledge of their chronic disease. Archives of Internal Medicine 158(2): 166 - 172

\section{Answers to Questions FOR CPD Points (Vol 59 No 3 )}
1. a
4. b
7. c
2. d
5. d
8. d
3. c
6. b
9. b

10. c 